\title{
The New Era of Regional Coastal Bathymetry from Space: A Showcase for West Africa using Sentinel-2 Imagery
}

\author{
Christopher Daly ${ }^{\mathrm{a}, *}$, Wassim M. Baba ${ }^{\mathrm{b}}$, Erwin W. J. Bergsma ${ }^{\mathrm{c}}$, Rafael \\ Almar $^{\mathrm{a}}$, Thierry Garlan ${ }^{\mathrm{d}}$ \\ ${ }^{a}$ LEGOS/IRD, UMR-5566, 14 Avenue Edouard Belin, 31400 Toulouse, France \\ ${ }^{b}$ LEGOS/CNRS, UMR-5566, 14 Avenue Edouard Belin, 31400 Toulouse, France \\ ${ }^{c}$ LEGOS/CNES, UMR-5566, 14 Avenue Edouard Belin, 31400 Toulouse, France \\ ${ }^{d}$ SHOM, 13 rue du Chatellier, 29200 Brest, France
}

\begin{abstract}
Large-scale coastal bathymetry is an essential data product for use in coastal research and governance. Traditional methods of measuring bathymetry, using sonar deployed from ships, take an enormous amount of time to collect and process, and thus prevent the gathering of data at high spatial and temporal resolution at a regional scale. Space-borne missions, such as the European Space Agency's Sentinel-2 mission, offer a solution to this limitation by frequent sensing at a global scale, with repeat observations every 5 days at the equator or less at higher latitudes. Satellite-derived bathymetry has often been associated with methods which exploit water colour to invert depth. However, depth can also be inverted from wave celerity using the linear dispersion relation. Here, we use a recently developed algorithm, S2Shores (Satellite to Shores), to extract wave celerity from the Sentinel-2 dataset by exploiting the small temporal offset between the image bands of its MultiSpectral Instrument. The resulting bathymetry estimates are then merged to create a mosaic of composite depth estimates spanning $4000 \mathrm{~km}$ along the West African coast. Given the scarcity of in-situ measured bathymetry in the region, the resulting atlas is compared to GEBCO, a global bathymetry dataset created by assimilating ship soundings with altimeter data. S2Shores is able to detect depths up to 20-40 $\mathrm{m}$ for West Africa, depending on mean
\end{abstract}

\footnotetext{
*Corresponding Author: christopher.daly@ird.fr
} 
incident wave conditions and cloud cover, which varies by location. Shallow water features between 2-15 m are well reproduced by S2Shores, such as flow channels in Guinea, the St. Ann's Shoal in Sierra Leone, and ebb delta lobes at several outlets along the Niger River Delta. Bathymetry data for the Senegalese coast is used to validate the S2Shores results, with very good results in shallow water. This new Coastal Atlas of West Africa opens the door to increased research and planning capabilities for the region, and sets an example that can be applied to the rest of the world.

Keywords: Optical Imagery, Waves, West Africa, Underwater Features, Satellite-Derived Bathymetry

\section{Introduction}

Accurate, highly resolved $O(100 \mathrm{~m})$ coastal bathymetry is a vital dataset heavily used in science, industry, governance, military and civilian applications, as the change of bathymetry provides fundamental understanding of the natural behaviour of coastlines and the impacts of engineering projects, and it serves as a boundary condition for numerical studies. Traditionally, acoustic (single-track and multi-beam echo sounders) methods have been used to collect bathymetry data; but even with the best efforts, it is not cost-effective for mapping coastal areas on a regional or even global scale, as only $18 \%$ of the world's oceans and $50 \%$ of coastal areas have been surveyed at 1-minute resolution (Becker et al. (2009); GEBCO Compilation Group (2019)). As such, the hydrographic community has turned to remote sensing techniques to help fill gaps between sparse records of acoustically-measured depths. The General Bathymetric Chart of the Oceans (GEBCO, (GEBCO Compilation Group, 2019)), one of few publicly available global bathymetry datasets, is created by using the gravity anomaly from satellite altimetry data, which is related to variations in-depth, to interpolate depths between in-situ soundings (Smith and Sandwell, 1997, 2004). As most soundings are located in deep oceanic waters, coastal areas $(<100 \mathrm{~m}$ depth $)$ are often poorly resolved, especially where there are abrupt changes in the shelf-slope, resulting in unrealistic representation of shallow features such as deltas and atolls. The quality of GEBCO depth estimates is also limited by the sparsity of its source data, especially in data-poor regions such as West Africa. Coastal bathymetric surveys in this area are 30 years old on average (as 
shown in GEBCO metadata ${ }^{1}$ ). The lack of detailed coastal bathymetric data leads to unacceptable uncertainties in coastal wave and flood models, in subsequent risk assessments and forecasts, and currently limits the best coastal management strategies for the region (Ndour et al. (2018)).

Additional methods of direct depth measurement using Earth Observation remote sensing techniques are therefore needed to produce large-scale (i.e. regional to global) bathymetries (Salameh et al., 2019). This may be achieved using aircraft (e.g. LiDAR) or satellite-derived bathymetry (SDB), either using radar or optical missions. For the latter, the two most advanced techniques which allow direct measurement of depth by satellite are watercolour (Stumpf et al., 2003; Lyzenga et al., 2006; Lee et al., 2010; Hodúl et al., 2018) and wave kinematics (Poupardin et al., 2016; Danilo and Melgani, 2016; Almar et al., 2019a; Bergsma et al., 2019b). SDB methods which rely on colour and light absorption as a proxy from which to estimate depth are limited to shallow water - with maximum detectable depths of approximately $15 \mathrm{~m}$, absolute errors of $\sim 30 \%$ of the target value, and root-meansquare errors up to $4 \mathrm{~m}$ (Pacheco et al., 2015; Chénier et al., 2018; Traganos et al., 2018). These methods are sensitive to local environmental conditions which affect water clarity, such as turbidity and bottom vegetation, and light absorption in the atmosphere. Methods using wave kinematics, on the other hand, exploit timing differences between a sequence of satellite images (or image bands) of the sea surface taken in rapid succession to detect the movement of surface waves. For example, satellite images from the Pleiades satellite mission (Airbus/CNES) can collect a burst of up to 12 high-resolution $(0.5 \mathrm{~m})$ images timed $8 \mathrm{~s}$ apart Almar et al. (2019a), while the Multi-Spectral Instrument (MSI) of the Sentinel-2 mission (ESA), collects surface reflectance data with a maximum $1.005 \mathrm{~s}$ interval between 10 $m$ resolution bands. Various analytic techniques can then be used to extract celerity data from the image sequences, either in the temporal (Almar et al., 2019a) or spectral-domain (Bergsma et al., 2019a).

Here, we use a recently developed method for estimating coastal bathymetry using multiple Sentinel-2 colour-bands (Bergsma et al., 2019a,b). The method, called Satellite to Shores (hereafter S2Shores), exploits the time difference between the blue and red colour bands in Sentinel RGB images (2 frames taken $1.005 \mathrm{~s}$ apart) to track the movement of surface waves over time and space.

\footnotetext{
${ }^{1}$ https://maps.ngdc.noaa.gov/viewers/iho_dcdb
} 
A novel localized Radon Transform combined with a Discrete fast Fourier Transform (DFT) technique is used to determine the dominant wave direction and corresponding wavelength and celerity at the peak image intensity. Water depths can then be inverted using the linear dispersion relationship with reasonable accuracy. Using wave kinematics as input allows maximum depths up to $100 \mathrm{~m}$ to be detected (theoretically) under optimal wave conditions (i.e. long swell) (Bergsma and Almar, 2020). This breakthrough technique, therefore, allows depth estimation in most coastal environments exposed to waves without dependence on water clarity or atmospheric light absorption (Bergsma and Almar, 2020).

Here we present the first regional SDB atlas along the West African coast (West Coast and Gulf of Guinea, from Senegal to Gabon). In this region, $253,970 \mathrm{~km}^{2}$ of the continental shelf lies within a depth range of $0-100 \mathrm{~m}$ (coastal zone), based on GEBCO data. Of this coastal zone, 18\% (70,700 $\mathrm{km}^{2}$ ) lies between $0-15 \mathrm{~m}$ depth - the sensing range of most colour-based methods. On the other hand, $70 \%\left(178,060 \mathrm{~km}^{2}\right)$ of the target area lies between 2-50 $\mathrm{m}$ depth — the average sensing range of most wave-based methods for this region (Bergsma and Almar, 2020).

\section{Methods}

\subsection{Area of Interest}

The area of interest (AoI) spans the coastal area of West Africa and the Gulf of Guinea between Senegal and Gabon. This $4000 \mathrm{~km}$ length of coastline, covered by 73 Sentinel-2 tiles, consists of a wide range of coastal features and types, including long sandy beaches, barrier islands, rocky capes, submarine canyons, offshore islands, estuaries, and deltas (Fig. 1). The width of the shallow coastal zone in the AoI varies considerably. It is widest $(<25$ $\mathrm{km}$ ) in the deltaic region spanning the Gambia, Guinea-Bissau, Guinea and Sierra Leone (the Guinea Terrace) (McMaster et al., 1970; Anthony, 2004), and along the Niger Delta. It is mildly sloping in Senegal (10-20 km wide), the Bight of Benin and Bonny, and most narrow $(>5 \mathrm{~km}$ ) along the coast of Liberia, immediately north of Dakar and around Bioko Island, Equatorial Guinea.

The West African coast from Senegal to Liberia generally faces westerly Atlantic swells, while Ivory Coast to Nigeria is exposed to south Atlantic swells (Almar et al., 2019b). Cameroon to Gabon, in the Bight of Bonny (Biafra), is relatively sheltered by offshore islands (e.g. Bioko, Equatorial 


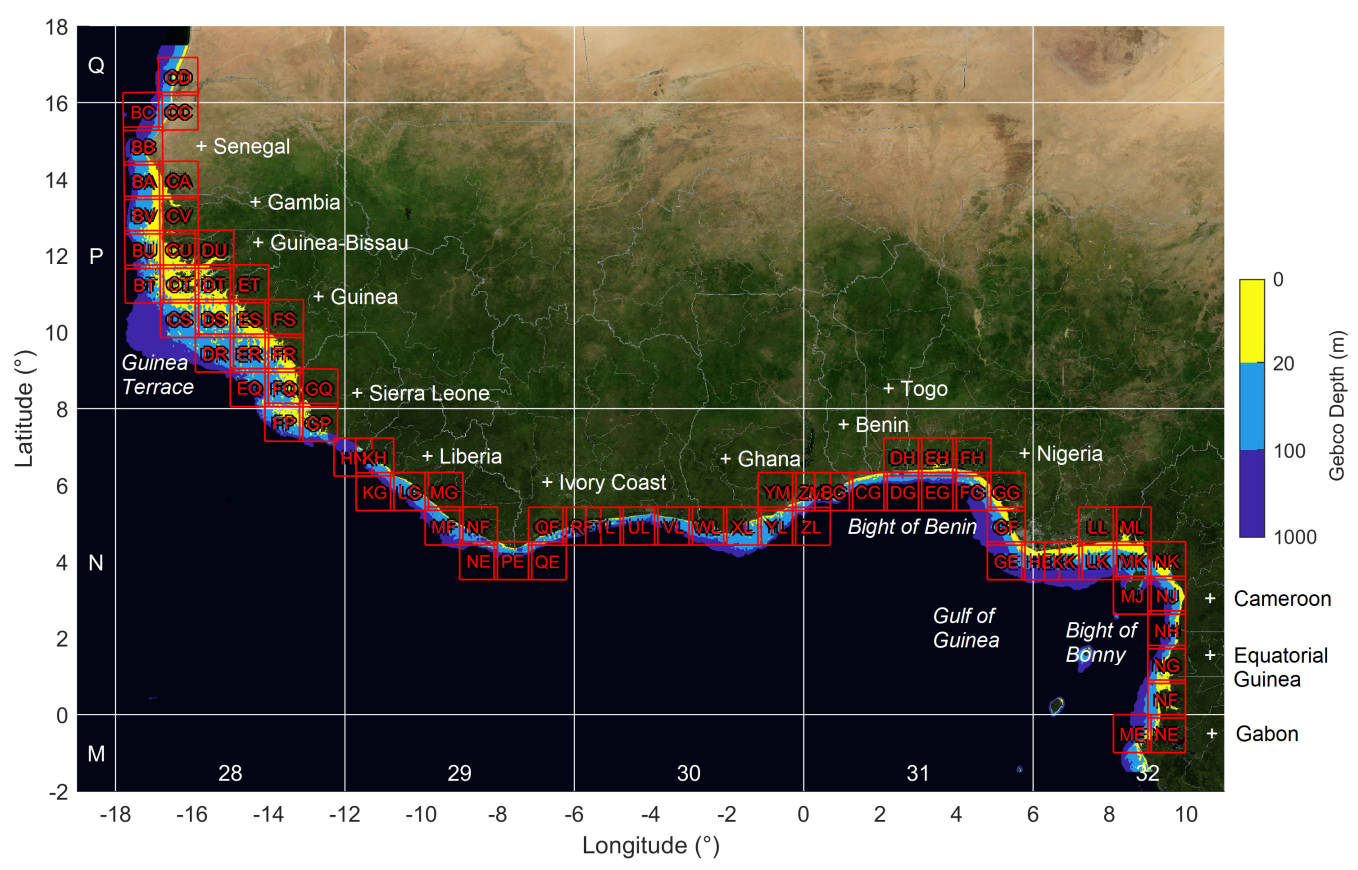

Figure 1: Area of interest in West Africa and Gulf of Guinea, from Senegal in the north to Gabon in the south. GEBCO bathymetry contours shown at 0, 20, 100 and $1000 \mathrm{~m}$ depths. The 73 red squares show the group of Sentinel 2 coastal tiles making up the study area, along $400 \mathrm{~km}$ of coastline. Each tile is $109 \times 109 \mathrm{~km}$. The name of each tile is constructed by using the UTM zone corresponding to the coordinates of its lower left corner as a prefix (UTM zone grid shown in white) and a sub-UTM zone identifier as a suffix (shown at the center of each square, in red). For example, 28PBB is the tile where Dakar, Senegal (the westernmost point in Africa) is located. Background image: MODIS Blue Marble, NASA Earth Observatory.

Guinea). Seasonality in wave conditions is observed along the entire West African coast. The Volta and Niger rivers produce the two largest deltas along the coast. Sediment supply from these deltas is constantly moved alongshore by long swell waves which drive persistent eastward longshore transport between Ghana and Nigeria (Anthony et al., 2016; Almar et al., 2015; Giardino et al., 2018). As such, these areas are susceptible to ongoing erosion at the western side and accretion at the east (Dada et al., 2016; Anthony et al., 2019).

Mean cloud cover varies over the AoI, with occasional cloud cover at Senegal (coastal area in close proximity to the Sahara Desert), with $<20 \%$ coverage $50 \%$ of the time, and increasingly persistent cloud cover further 
south in tropical equatorial regions, especially in the Bight of Bonny, with up to $<80 \%$ coverage $50 \%$ of the time (Bergsma and Almar, 2020).

Six 'hot-spots' are identified within the AoI, covering the full range of coastal types. They are, namely, Senegal, Guinea, Sierra Leone, Volta Delta, Niger Delta, and Cameroon. The hot-spots are excellent validation sites for the S2Shores model because of the diverse range of coastal features, wave exposure and cloud cover at each location.

\subsection{Pre-Selection and-Treatment of Satellite Images}

The recently launched Copernicus Sentinel-2 Mission ${ }^{2}$ captures multispectral satellite image data every 5 days at the equator. There are therefore approximately 6 images per month at a particular location which may be used for depth estimation. Each Sentinel-2 satellite image has 13 spectral bands with a footprint of $109.8 \times 109.8 \mathrm{~km}$. Of the 13 spectral bands, four are sampled at 10-meter resolution, of which three represent visible colours blue, green and red (bands 2-3-4, respectively), while band 8 represents the near-infrared (NIR) part of the electromagnetic spectrum. Data from bands 3 and 8 are used in the analysis of pre-selection and subsequent treatment.

The Sentinel-2 image database currently spans a period of 5 years from 2015 to present, resulting in at least 200 images per tile (single orbit). With such a large number of observations, a global analysis including all images will be inefficient and unconscionable, thus here the best images are selected and analysed. Images that are likely to produce the best results are those which are relatively cloud-free, and have observable wave-fields (the greater the wave height, the better) and which travel at sufficient speed such that changes in phase can be easily detected (the longer, the better). The combination of these two criteria makes the wave power $\left(\alpha\right.$ height $^{2} \times$ period $)$ an obvious and effective proxy for selecting the best times for carrying out the analysis. As such, hindcast wave data from the European Centre for MediumRange Weather Forecasts (ECMWF) ERA5 global dataset (Dee et al., 2011; Copernicus Climate Change Service (C3S), 2017) was used to determine the background wave conditions and cloud cover for each image of the 72 selected West Africa tiles between September 2015 and February 2020. The data was sorted to minimise cloud cover (top 50 per tile) and, subsequently, maximise the wave power (top 30 per tile).

\footnotetext{
${ }^{2}$ https://sentinel.esa.int/web/sentinel/missions/sentinel-2
} 
For analysis in S2Shores, following Baba et al. (In Prep), each top-30 image is broken down into $3618.3 \times 18.3 \mathrm{~km}$ sub-images for parallel computation on a multi-core processor high-performance computing server (HAL, CNES). Depth estimates are produced on a $200 \times 200 \mathrm{~m}$ output grid, with therefore just over 300,000 depth estimates per image (if completely covered by water). A global land mask at $150 \mathrm{~m}$ resolution, produced by the ESA Climate Change Initiative ${ }^{3}$ (Lamarche et al., 2017), is used to identify land areas which are excluded from the computations. For a detailed explanation of the computational implementation of S2Shores, the reader is directed to Baba et al. (In Prep).

\subsection{Bathymetry Estimation}

Depth estimates are produced according to the method outlined in Bergsma et al. (2019b), which uses a combined Radon and discrete fast-Fourier transform method (hereafter, RT and DFT), also known as Fourier-Slicing, to detect wave signals within a sub-window of the satellite image. Depth estimation is repeated for each sub-window around a point where one wants to know the depth $(h)$. The sub-window should be large enough to contain $1-2$ wavelengths $(\lambda)$. Thus, a minimum window size of $300 \mathrm{~m}$ is used at the shoreline, and increases incrementally -following the formulation in Bergsma et al. (2019b) - up to a maximum of $600 \mathrm{~m}$ in areas farther from land (10 $\mathrm{km}$ ), where depths are expected to be greater and wavelengths longer. The RT of the wave signal in the sub-window produces a sinogram of integrated pixel intensities per direction. The wave direction is determined as the angle corresponding to the maximum variance in the RT-sinogram. The DFT of the RT enables the spectral phase of the waveforms to be determined per direction, the difference of which $(\Delta \Phi)$ can be found between several pairs of detector bands. Presuming that the wavenumber $(k)$ is constant or nearconstant over the sub-window, $\Delta \Phi$ can be seen as representative of $\omega(t)$, and given that the timing between the different detector bands $(\Delta t)$ is constant, the wave celerity $(c)$ can be determined as:

$$
c=\frac{\Delta \Phi}{2 \pi k \Delta t}=\frac{\Delta \Phi \lambda}{2 \pi \Delta t}
$$

For each wave-number or celerity pair, (2) can be solved for depth.

\footnotetext{
${ }^{3}$ http://maps.elie.ucl.ac.be/CCI/viewer
} 


$$
c^{2}=\frac{g}{k} \tanh (k h) \Leftrightarrow h=\frac{\tanh ^{-1}\left(\frac{c^{2} k}{g}\right)}{k}
$$

Estimates of water depth, wave celerity, wavenumber (wavelength) and direction are output by the S2Shores algorithm at each point on an output grid with a resolution of $200 \mathrm{~m}$. This output data is further treated as outlined in the section following.

\subsection{Post-processing of Depth Estimates}

\subsubsection{Data Masking}

Masks are applied to the S2Shores output to remove unreliable depth estimates, primarily associated with clouds. Cloud masks are created using a simple threshold on the NIR band, assuming the majority of NIR radiation is absorbed by water bodies and reflected by clouds. A threshold of 0.02 is used on the normalized NIR reflectance (c.f. Banks and Mélin (2015)) to identify cloudy pixels, and areas within $100 \mathrm{~m}$ of such pixels are also masked. This NIR cloud mask removes most dense/opaque clouds; however, light cirrus clouds are not easily detected. Therefore, pre-made clouds masks from the Sentinel-2 database (Copernicus Data Access Portal, 2020) are also used to augment the NIR cloud mask.

Output data are also masked where unrealistic depth or celerity estimates occur. Given that the expected maximum (minimum) wave period is 20 (4) s, S2Shores should ideally detect wave celerity between $4-34 \mathrm{~m} / \mathrm{s}( \pm 10 \%)$ for depths ranging between $2-100 \mathrm{~m}$. Areas, where depth or celerity estimates are greater or less than this expected detection range, are removed from the analysis.

\subsubsection{Creation of Depth Composite and Mosaic}

After running S2Shores for the top-30 images for each of the 73 West Africa tiles, the 10 best (raw) results are selected to create a composite. This selection is based on minimising the error and maximising the correlation between the S2Shores results and GEBCO (between $2-45 \mathrm{~m}$ depth). It is then necessary to weight the raw depth results at each point to account for differences in wave conditions over time, as waves with longer period are able to sense deeper water depths. In 'shallow' water (raw mean depth $<20 \mathrm{~m}$ ) results closer to the median value are used, while in 'deep' water (raw mean depth $>20 \mathrm{~m}$ ) results closer to the maximum value are used. The final step 
is to smooth the (temporally) weighted depth with neighbouring points in space (within 2 grid cells, or a $1 \mathrm{~km}$ radius) to reduce artefacts. The final 73 depth composites are then tiled together to create a depth mosaic for the entire study area.

\subsection{Comparative Bathymetry Datasets}

S2Shores depth estimates have to be compared to measured data to determine its quality. Besides GEBCO, publicly available coastal bathymetry datasets are difficult to source for the study area and tend to be quite dated. Privately held data at the French Naval Hydrographic and Oceanographic Service (SHOM) was obtained for the Senegalese coast (hereafter referred to as the 'available data'), but not for the remaining portions of the West African coast. Therefore, comparisons made with the available data at the Senegal hot-spot will help to show the accuracy of the S2Shores results, while more general comparisons with GEBCO are made elsewhere.

\section{Results}

\subsection{Regional West African Bathymetry}

S2Shores estimates of the regional West African bathymetry are shown as a mosaic for all 73 selected Sentinel-2 coastal tiles (Figure 2). Depths are shown at a resolution of $1 \mathrm{~km}$ and are plot out to a distance of $45 \mathrm{~km}$ offshore (or to the extent of the $100 \mathrm{~m}$ contour line in GEBCO, whichever is greater), covering the contiguous coastal zone (12 nautical miles) of each member state. At this scale, it is possible to observe the extent of the upper, shallow portion of the shelf. It is widest between Guinea-Bissau and Sierra Leone, and at the Niger Delta, and most narrow between Liberia, Ivory Coast and Ghana. At this scale, deep features (>30 m depth, such as submarine trenches) are not easily distinguished from the general background. However, more shallow features, such as ebb delta channels around the Bissagos Islands (Guinea-Bissau) and the St. Ann's Shoal in Sierra Leone are captured very well.

\subsection{Zoom at Hot-Spots}

Figure 3 shows close-ups of the S2Shores depth composites at the six hotspots compared to GEBCO, highlighting the ability of the model to discern depth patterns at a local scale. Here, the data is shown at $200 \mathrm{~m}$ resolution and at least up to $30 \mathrm{~km}$ from the shoreline. 


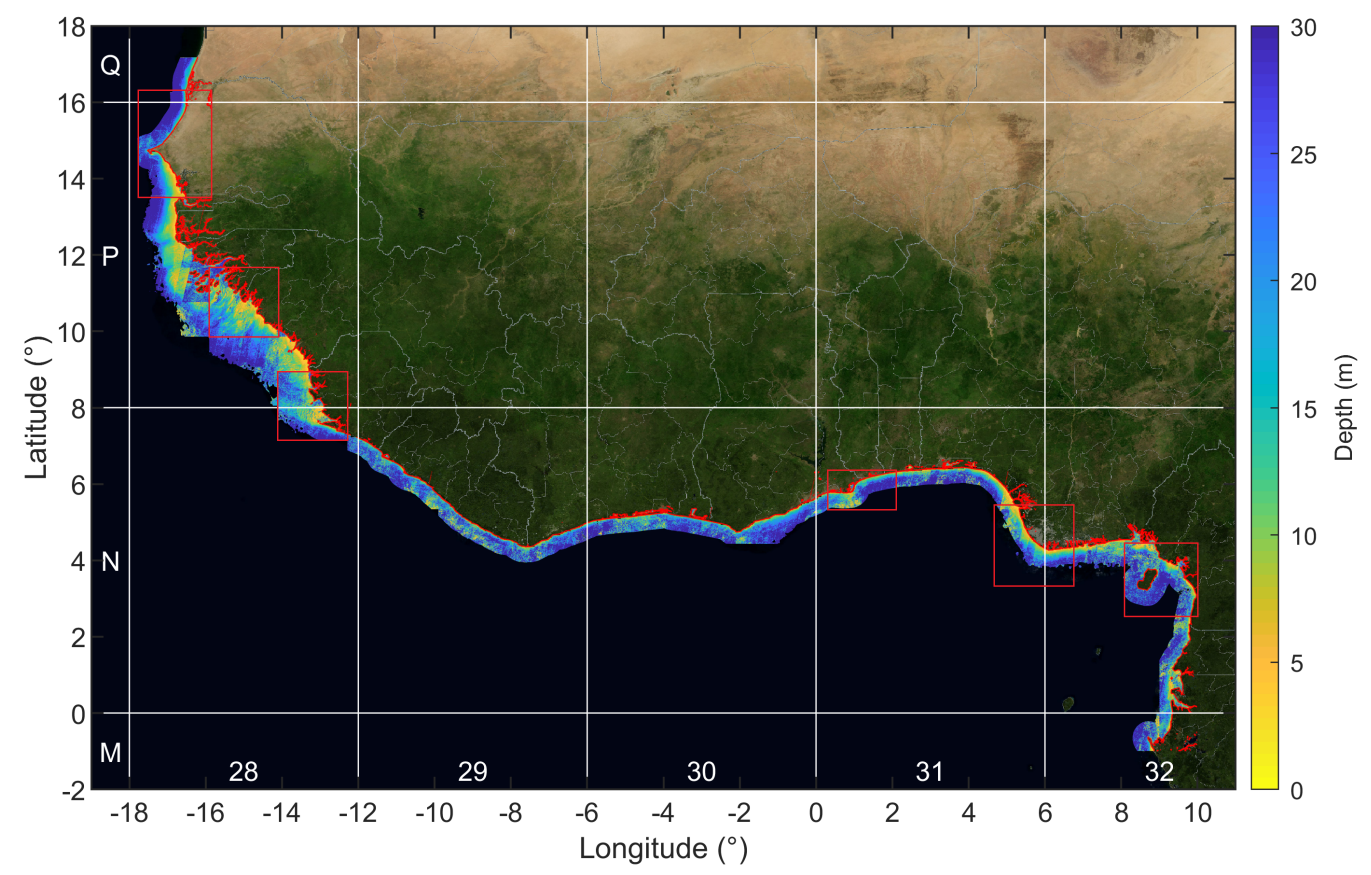

Figure 2: Mosaic of S2Shores bathymetry composites for the West Africa Region. Color scale shows depths between $0-30 \mathrm{~m}$, the red line shows the shoreline, and UTM zones shown in white. Red boxes outline the area of the six hot-spots. Background image: MODIS Blue Marble, NASA Earth Observatory.

The best comparison between GEBCO and S2Shores is at Senegal (Figure $3 \mathrm{a}-\mathrm{b})$. As mentioned in Section 2, this section of the West African coast is exposed to long-period Atlantic swell. This, coupled with low cloud cover on average, allows S2Shores to predict smooth transitions from deep to shallow water. The area immediately south of the Dakar peninsula is well-predicted despite the more restrictive conditions for obtaining viable estimates, due to wave shadowing effects of the Dakar peninsula and the change in orientation of the shoreline concerning the incident wave field. The shallow area of the remaining portion of the coast in the south broadens as expected, compared to GEBCO, heading toward the deltaic region of Guinea-Bissau. Maximum depth estimates at this location are approximately $40 \mathrm{~m}$.

In contrast to Senegal, maximum depth estimates at the Cameroon hotspot (Figure $3 \mathrm{k}-\mathrm{l}$ ), located in the Bight of Bonny, are shallower at around $22 \mathrm{~m}$, primarily due to lower wave periods and a vast reduction in usable data after masking out clouds. However, despite the year-round high cloud 

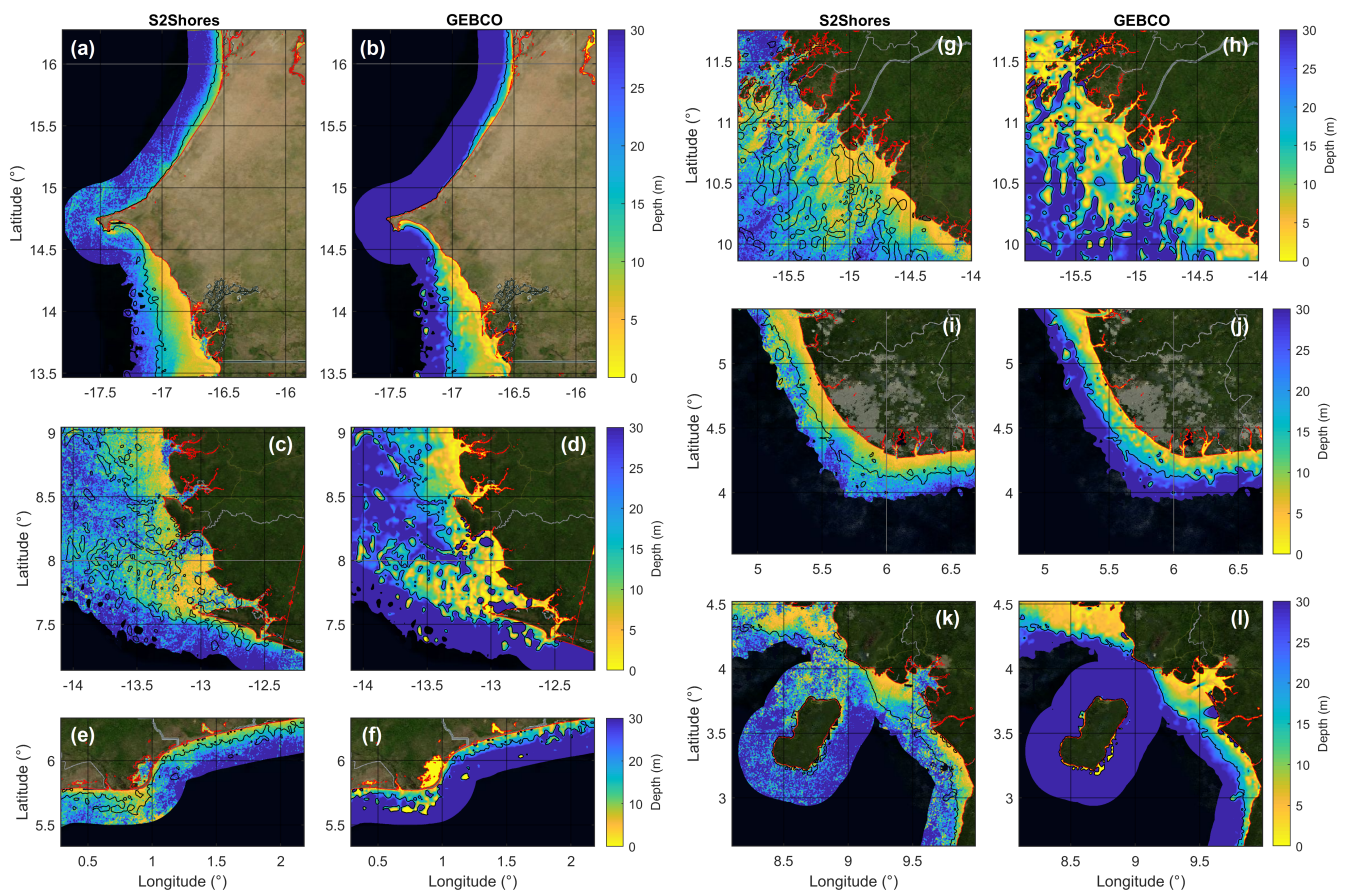

Figure 3: Comparison between S2Shores bathymetry composite and GEBCO for the six hot-spots. (a-b) Senegal (tiles 28PCC, 28PBB, 28PBA, 28PBC and 28PCA). (b-c) Sierra Leone (tiles 28PFQ, 28PGQ, 28NFP and 28NGP). (e-f) Volta Delta (tiles 30NBG and 30NCG). (g-h) Guinea (tiles 28PDS, 28PTS, 28PET and 28PDT). (i-j) Niger Delta (tiles 31NHE, 31NGE and 31NGF). (k-l) Cameroon (tiles 32NNK, 32NNJ, 32NMK and 32NMJ). Color scale shows depths between 0-30 m, the black line shows the $20 \mathrm{~m}$ GEBCO depth contour, and the red line shows the shoreline. Background image: MODIS Blue Marble, NASA Earth Observatory.

cover, quite good estimates of shallow nearshore banks at the entrance to the Wouri estuary are obtained, as can also be seen in GEBCO. As the shelf around Bioko Island (Equatorial Guinea) is extremely narrow, there are limited shallow S2Shores results there, similar to GEBCO.

At the Sierra Leone and Guinea hot-spots (Figure $3 \mathrm{c}-\mathrm{d}$ and $\mathrm{g}-\mathrm{h}$ ), shallow features present on the wide continental shelf are detected by S2Shores. Channel features at the Guinea hot-spot are more clearly resolved by S2Shores than GEBCO. In fact, the GEBCO estimates for the same area show sporadic blobs where depths vary from deep to shallow, with little alignment toward a natural offshore flow direction of the channels. The defining shallow water feature at the Sierra Leone hot-spot is the St. Ann's shoal, located north- 

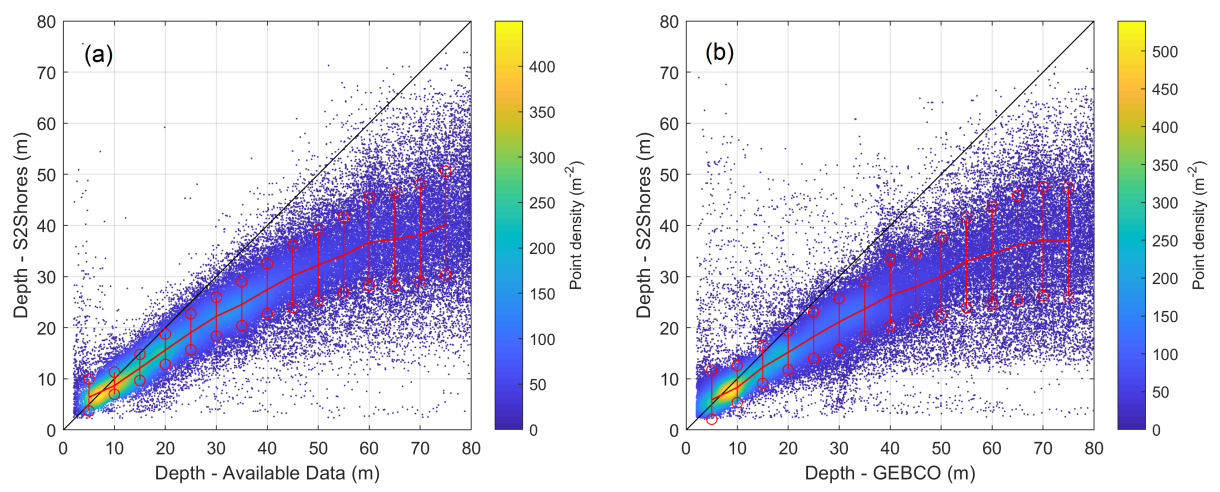

Figure 4: Scatter plot of S2Shores depth estimates against available data at Senegal (a) and Volta Delta (b). Black line indicates the target depth (1:1 comparison), the red line shows the mean trend of the S2Shores estimates in $5 \mathrm{~m}$-wide bins, and the red circles show the standard deviation about the mean of each bin. Colour scale indicates the density of points within a $1 \mathrm{~m}^{2}$ area of the plot.

west of the Turtle and Sherbro Islands. Here, rhythmic underwater dune features are discernible in the S2Shores results, with heights between 8-12 $\mathrm{m}$ and wavelengths of 6-7 km. Predicted S2Shores depths on the wide continental shelf around the Guinea and Sierra-Leone hot-spots are limited by its inherent shallowness, with depth saturation at 20 and $27 \mathrm{~m}$, respectively. However, the southern edge of the shelf in Sierra Leone is clearly shown down to depths of $35 \mathrm{~m}$.

At the Volta Delta, S2Shores shows similar depth patterns as GEBCO to the east of the delta apex, but generally shallower depths to the west. The shelf is wider in the west, extending up to $20 \mathrm{~km}$ offshore, and is about $10 \mathrm{~km}$ in the east. S2Shores appropriately captures the location of sharp changes in depth at the shelf edge, which starts to drop steeply after $25 \mathrm{~m}$ depth. The Niger Delta area is also nicely estimated by S2Shores, with deep channels seen at the mouth of the Niger river at Forcados, and crescent-shaped outer delta lobes at several other mouths such as at Digatoro, Sangan, Nun and Brass. Shallow areas (down to $20 \mathrm{~m}$ ) extend further seaward in the S2Shores predictions than GEBCO, with a depth saturation occurring at $30 \mathrm{~m}$.

\subsection{Validation Error at Senegal}

The quality of the S2Shores results is assessed by comparing output at the Senegal hot-spot to the available bathymetric data (and to GEBCO). High correlation coefficients $\left(r^{2}\right)$ are obtained for depths between 2-35 m, with a 
value of 0.78 for the available data (and 0.62 for GEBCO). The linear best-fit for the same depth range has a gradient of 0.64 and intercept of $3.0 \mathrm{~m}$, for the available data. Scatter plots of the results (Figure $4 \mathrm{a}$ and $\mathrm{b}$ for the available data and GEBCO, respectively) show that as the target depth increases, S2Shores tends to increasingly underestimate its value. This response is expected, however, as ever longer waves are required to sense small changes in celerity in deeper waters, leading to the saturation of depth estimates as the target depth increases. Thus, the mean trend of the S2Shores estimates begins to flatten out at around $40 \mathrm{~m}$ compared to the available data $(37 \mathrm{~m}$ compared to GEBCO). Despite this, estimates in shallow water (between 2$15 \mathrm{~m}$ ), where majority of the depth estimates lie, are very close to the target depth. There, the absolute error is approximately $20 \%$ of the target value on average, with the root-mean-square-error (RMS error) and bias being 3.0 and $-0.5 \mathrm{~m}$, respectively.

\section{Discussion}

\subsection{Performance of S2Shores}

The results have shown that S2Shores is able to detect depths down to 40 $\mathrm{m}$ under ideal conditions, as is the case for Senegal which experiences long swell and low cloud cover for most of the year. This depth range is up to three times greater than the typical range of colour-based SDB methods. Furthermore, the estimation of depth over such a large area for the West African coastal zone, $O\left(100,000 \mathrm{~km}^{2}\right)$, is quite unique for SDB methods, which are normally carried out in very localized areas $O\left(1,000 \mathrm{~km}^{2}\right)$. For the hot-spots, depths below $15 \mathrm{~m}$ are well estimated and many shallow-water features are apparent. As shown Figure 4, estimated depths begin to diverge from the target depth below $20 \mathrm{~m}$. However, if a larger number of observations are used in making the composite (besides only the top-10), the probability of retrieving better deepwater estimates under ideal wave and cloud cover conditions will be increased. This, however, is a limitation of computational resources rather than the method itself. However, in future developments, it may be possible to develop site-specific corrections for depths below $20 \mathrm{~m}$.

\subsection{Dependency of Quality on Meteorological Conditions}

The S2Shores algorithm produces useful estimates once a distinct wavefield can be observed. However, in reality, the actual variation of pixel in- 
tensities is heavily influenced by meteorological conditions of the wave field and atmosphere, and to a lesser extent by water colour transitions.

By analysing the result of one years' worth of observations at the Senegal and Volta hotspots (72 Sentinel-2 images at tiles 28PCC and 31NBG), several error parameters were determined: namely the bias, root-mean-square error, correlation $\left(r^{2}\right)$ and slope of the linear regression between S2Shores estimates and available data. A quality flag was also manually attached to each estimate to signify whether the S2Shores result was good, mediocre or bad. Good estimates had clear transitions of depth from shallow to deep, mediocre results tend to be monotonous, and bad results have significant depth artifacts, mainly as a result of high cloud cover coupled with imperfect cloud masks.

Fitting a multiple linear regression model of various local wave meteorological parameters (e.g. significant wave height, wind direction) to the measured error allows us to determine which are most influential. From this analysis, the $r^{2}$ and bias are consistently the best error descriptors, and the mean period of swell waves, the wave power, directional spreading and cloud cover are consistently among the most influential parameters affecting the result of the S2Shores estimate. Powerful swell waves (with large heights and long wavelengths/periods) travel faster than the background wind waves and are more easily detected in the algorithm. These waves also allow for deeper estimates of depth. Narrow banded swell reduces potential cross-sea patterns, which may create multiple peaks in the directional space of the pixel intensity. Furthermore, short steep waves (even if they are less energetic) may have a larger optical signature than longer, flatter waves, which results

in an under-estimation of the depth. While opaque clouds block the view of the sea surface, light cirrus clouds, fog or atmospheric dust also obscure the field of view and lead to unreliable estimates.

\subsection{Perspectives}

The ability to frequently and accurately monitor bathymetric changes over large scales will significantly help to broaden our understanding of dynamic coastal processes and their coupling to large-scale forcing conditions. While we have currently used images taken over a 5-year period, S2Shores composites computed over shorter time periods offer the possibility to create unique time series of bathymetry and thus observe dynamic changes of shallow water features, such as delta formations or underwater dune migration. 
Producing composites of seasonal (3-4 months) to weekly changes (at or near the satellite revisit time) in bathymetry at regional scales are possible; however, accurate sensing of depths below $20 \mathrm{~m}$ will depend heavily on the probability of occurrence of successive high energy wave conditions over a short space of time. Thus, detecting bathymetric changes with reasonable accuracy over short periods will most likely be limited to shallow water $<$ $15 \mathrm{~m}$. Nonetheless, as bathymetric changes tend to be more rapid in shallow water than deepwater, depth changes may still be detected over the entire water column at various timescales with adaptive windowing.

Finally, the 73 Sentinel-2 tiles selected for the West Africa atlas represents $1 \%$ of the global list of Sentinel-2 coastal tiles, with depths between 0-100 m. With such promising results as shown, there is definite potential for the method to be further applied on a global scale. The spatial resolution of the estimates may also be decreased from the $200 \mathrm{~m}$ used for this study (initial tests were carried out on a $100 \mathrm{~m}$ grid). A lower limit of $50 \mathrm{~m}$ is possible, and would potentially permit the visualisation of features such as sandbars. However, it would come at a much higher computational cost, and would therefore be more suited for generating datasets at a local level.

\section{Conclusion}

Most coastal areas in the world suffer from a lack of existing quality bathymetry, with no or decades old observations. Satellite Earth observation opens the new era of measuring coastal bathymetry from space. However, commonly used colour based depth inversion methods are often limited in turbid coastal areas. The S2Shores algorithm, based on extracting wave kinematics from within Sentinel-2 multi-spectral image bands, has been used to produce unprecedented fine resolution $O(100 \mathrm{~m})$ regional-scale coastal bathymetry from satellite along $4000 \mathrm{~km}$ of the West African coastline and almost $70 \%$ of the coastal zone of the continental shelf. The method is able to detect depths down to $40 \mathrm{~m}$, and offers the potential to monitor the dynamics of shallow coastal features, such as deltas, shoals and underwater dunes. This new Coastal Atlas of West Africa opens the door to increased research and planning capabilities for the region, and sets an example that can be applied to the rest of the world, on a regular basis. 


\section{Acknowledgements}

This study was carried out as part of the project MEPELS, performed under the auspices of the DGA, and led by SHOM. E.B. was funded through a post-doctoral fellowship of the French Space Agency (CNES). The authors would like to thank members of the PEPS and HAL teams at the CNES Calculation Center, especially Christophe Taillan, Erwann Poupart, Guillaume Eynard-Bontemps, Florent Ventimiglia, and Sylvain Rigole, for providing technical support in accessing the Sentinel data products and developing parallel computing scripts for the CNES High Performance Cluster.

\section{Author Contributions}

Conceptualization: RA and EB. Methodology and Data Processing: EB, WB and CD. Data Analysis and Interpretation: CD. Writing - Original Draft: CD. Writing - Review and Editing: All authors. Project Administration and Funding: RA and TG.

\section{References}

Almar, R., Bergsma, E.W.J., Maisongrande, P., Almeida, L.P.M., 2019a. Wave-derived coastal bathymetry from satellite video imagery: A showcase with pleiades persistent mode. Remote Sensing of Environment 231, 8 pp.

Almar, R., Kestenare, E., Boucharel, J., 2019b. On the key influence of remote climate variability from tropical cyclones, north and south atlantic mid-latitude storms on the senegalese coast (west africa). Environmental Research Communications 1, 11 pp. doi:https://doi.org/10.1088/2515$7620 /$ ab2ec6.

Almar, R., Kestenare, E., Reyns, J., Jouanno, J., Anthony, E., Laibi, R., Hemer, M., DuPenhoat, Y., Ranasinghe, R., 2015. Response of the bight of benin (gulf of guinea, west africa) coastline to anthropogenic and natural forcing, part1: Wave climate variability and impacts on the longshore sediment transport. Continental Shelf Research 110, 48-59.

Anthony, E., Almar, R., Aagaard, T., 2016. Recent shoreline changes in the volta river delta, west africa: the roles of natural processes and human impacts. African Journal of Aquatic Science 41, 81-87. doi:http://dx.doi.org/10.2989/16085914.2015.1115751. 
Anthony, E., Almar, R., Besset, M., Reyns, J., Laibi, R., Ranasinghe, R., Abessolo Ondoa, G., Vacchi, M., 2019. Response of the bight of benin (gulf of guinea, west africa) coastline to anthropogenic and natural forcing, part 2: Sources and patterns of sediment supply, sediment cells, and recent shoreline change. Continental Shelf Research 173, 93--103.

Anthony, E.J., 2004. The turtle bank, sherbro bay, west africa: estuarinemodified inner shelf shoal?, in: Proceedings of Marine Sandwave and River Dune Dynamics, Enschede, the Netherlands. p. 8 pp.

Baba, W.M., Bergsma, E.W.J., Almar, R., Daly, C.J., In Prep. Deriving large-scale coastal bathymetry from sentinel-2 images using a highperformance cluster. Consideration for Remote Sensing (MDPI) .

Banks, A.C., Mélin, F., 2015. An assessment of cloud masking schemes for satellite ocean colour data of marine optical extremes. International Journal of Remote Sensing 36, 797-821.

Becker, J., Sandwell, D., Smith, W.H.F., Braud, J., Binder, B., Depner, J., Fabre, D., Factor, J., Ingalls, S., Kim, S.H., Ladner, R., Marks, K., Nelson, S., Pharaoh, A., Trimmer, R., von Rosenberg, J., Wallace, G., Weatherall, P., 2009. Global bathymetry and elevation data at 30 arc seconds resolution: Srtm30_plus. Marine Geodesy 32, 355-371. doi:10.1080/01490410903297766.

Bergsma, E.W.J., Almar, R., 2020. Coastal coverage of esa' sentinel 2 mission. Advances in Space Research 65, 2636-2644. doi:https://doi.org/10.1016/j.asr.2020.03.001.

Bergsma, E.W.J., Almar, R., Maisongrande, P., 2019a. Radon-augmentation of sentinel-ii imagery to enhance resolution and visibility of (nearshore) ocean-wave patterns, in: Proceedings of the International Geoscience and Remote Sensing Symposium (IGARSS), IEEE, Yokohama, Japan. pp. 7944-7947. doi:10.1109/IGARSS.2019.8898181.

Bergsma, E.W.J., Almar, R., Maisongrande, P., 2019b. Radonaugmented sentinel-2 satellite imagery to derivewave-patterns and regional bathymetry. Remote Sensing 11, 16 pp. doi:https://doi.org/10.3390/rs11161918. 
Chénier, R., Faucher, M.A., Ahola, R., 2018. Satellite-derived bathymetry for improving canadian hydrographic service charts. International Journal of Geo-Information 7, 15 pp.

Copernicus Climate Change Service (C3S), 2017. ERA5: Fifth generation of ECMWF atmospheric reanalyses of the global climate. Copernicus Climate Change Service Climate Data Store (CDS). URL: https://cds.climate.copernicus.eu/cdsapp\#!/home. accessed: 2020$01-24$.

Copernicus Data Access Portal, $2020 . \quad$ Sentinel2 msi level-1c cloud masks. URL: https://sentinel.esa.int/web/sentinel/technical-guides/sentinel-2-msi/level-1c/c accessed: 2020-02-26.

Dada, O.A., Li, G., Qiao, L., Ding, D., Ma, Y., Xu, J., 2016. Seasonal shoreline behaviours along the arcuate niger delta coast: Complex interaction between fluvial and marine processes. Continental Shelf Research 122, 51-67. doi:https://doi.org/10.1016/j.csr.2016.03.002.

Danilo, C., Melgani, F., 2016. Wave period and coastal bathymetry using wave propagation on optical images. IEEE Transactions on Geoscience and Remote Sensing 54, 6307-6319.

Dee, D.P., Uppala, S.M., Simmons, A.J., Berrisford, P., Poli, P., Kobayashi, S., Andrae, U., Balmaseda, M.A., Balsamo, G., Bauer, P., Bechtold, P., Beljaars, A.C.M., van de Berg, L., Bidlot, J., Bormann, N., Delsol, C., Dragani, R., Fuentes, M., Geer, A.J., Haimberger, L., Healy, S.B., Hersbach, H., Hólm, E.V., Isaksen, L., Kållberg, P., Köhler, M., Matricardi, M., McNally, A.P., Monge-Sanz, B.M., Morcrette, J.J., Park, B.K., Peubey, C., de Rosnay, P., Tavolato, C., Thépaut, J.N., Vitart, F., 2011. The era-interim reanalysis: configuration and performance of the data assimilation system. Quarterly Journal of the Royal Meteorological Society 137, 553-597. doi:10.1002/qj.828.

GEBCO Compilation Group, 2019. Gebco 2019 grid. URL: https://www.gebco.net/data_and_products/gridded_bathymetry_data/, doi:10.5285/a29c5465-b138-234d-e053-6c86abc040b9. accessed: 2019-1129 . 
Giardino, A., Schrijvershof, R., Nederhoff, C., de Vroeg, H., Brière, C., Tonnon, P.K., Caires, S., Walstra, D., Sosa, J., van Verseveld, W., Schellekens, J., Sloff, C., 2018. A quantitative assessment of human interventions and climate change on the west african sediment budget. Ocean and Coastal Management 156, 249-265. doi:https://doi.org/10.1016/j.ocecoaman.2017.11.008.

Hodúl, M., Bird, S., Knudby, A., Chénier, R., 2018. Satellite derived photogrammetric bathymetry. ISPRS Journal of Photogrammetry and Remote Sensing 142, 268-277. doi:https://doi.org/10.1016/j.isprsjprs.2018.06.015.

Lamarche, C., Santoro, M., Bontemps, S., d'Andrimont, R., Radoux, J., Giustarini, L., Brockmann, C., Wevers, J., Defourny, P., Arino, O., 2017. Compilation and validation of sar and optical data products for a complete and global map of inland/ocean water tailored to the climate modeling community. Remote Sensing 9, 20 pp.

Lee, Z., Hu, C., Casey, B., Shang, S., Dierssen, H., Arnone, R., 2010. Global shallow-water from satellite ocean color data. Eos 91, 429-430.

Lyzenga, D.R., Malinas, N.P., Tanis, F.J., 2006. Multispectral bathymetry using a simple physically based algorithm. IEEE Transactions on Geoscience and Remote Sensing 44, 2251-2259. doi:10.1109/TGRS.2006.872909.

McMaster, R., Lachance, T.P., Ashraf, A., 1970. Continental shelf geomorphic features off portuguese guinea, guinea, and sierra leone (west africa). Marine Geology 9, 203-213.

Ndour, A., Laïbi, R.A., Sadio, M., Degbe, Cossi G.E. andDiaw, A.T., Oyédé, L.M., Anthony, E.J., Dussouillez, P., Sambou, H., Dièye, E.h.B., 2018. Management strategies for coastal erosion problems in west africa: Analysis, issues, and constraints drawn from the examples of senegal and benin. Ocean and Coastal Management 156, 92-106.

Pacheco, A., Horta, J., C. Loureiro, C., Ferreira, O., 2015. Retrieval of nearshore bathymetry from landsat 8 images: A tool for coastal monitoring in shallow waters. Remote Sensing of Environment 159, 102-116. 
Poupardin, A., Idier, D., de Michele, M., Raucoules, D., 2016. Water depth inversion from a single spot-5 dataset. IEEE Transctions on Geoscience and Remote Sensing 54, 2329-2342.

Salameh, E., Frappart, F., Almar, R., Baptista, P., Heygster, G., Lubac, B., Raucoules, D., Almeida, L.P., Bergsma, E.W.J., Capo, S., De Michele, M., Idier, D., Li, Z., Marieu, V., Poupardin, A., Silva, P.A., Turki, I., Laignel, B., 2019. Monitoring beach topography and nearshore bathymetry using spaceborne remote sensing: A review. Remote Sensing 11, 32 pp. doi: $10.3390 /$ rs11192212.

Smith, W.H., Sandwell, D.T., 2004. Conventional bathymetry, bathymetry from space, and geodetic altimetry. Oceanography 17, 8-23.

Smith, W.H.F., Sandwell, D.T., 1997. Global sea floor topography from satellite altimetry and ship depth soundings. Science 277, 1956-1962.

Stumpf, R.P., Holderied, K., Sinclair, M., 2003. Determination of water depth with high-resolution satellite imagery over variable bottom types. Limnology and Oceanography 48, 547-556.

Traganos, D., Poursanidis, D., Aggarwal, B., Chrysoulakis, N., Reinartz, P., 2018. Estimating satellite-derived bathymetry (sdb) with the google earth engine and sentinel-2. Remote Sensing 10, 18 pp. 